\title{
Holistic Governance Applied in Customs-A Study based on the Perspective of Regional Integration
}

\author{
Yi-Xin Xu ${ }^{1, a,{ }^{*}}$, Cai-Hong Hou ${ }^{1, b}$, Xin-Yi Ye ${ }^{1, c}$ \\ ${ }^{1}$ Shanghai Customs Collage, West Huaxia Road, Pudong New Area, Shanghai, China

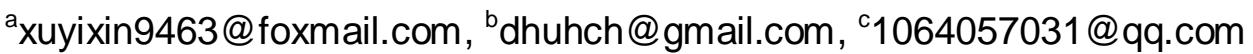 \\ ${ }^{*}$ Corresponding author
}

Keywords: Holistic governance theory, Regional integration, Customs clearance.

\begin{abstract}
Holistic governance theory is to explicit the responsibilities of every subject further under the circumstance of subjective disorder for the purpose of realizing the comprehensive coordination of multiple-subject and to avoid making the division of the privileges between the departments divided by domestic authorities vague. Recent years, China customs are propelling the regional integration reform of customs clearance, symbolizing a new milestone of China customs management and operation mode. However, regional integration refers to more than one customs offices and different government departments, which brought about Cross-departmental communication and cooperation. This article analyses the actuality of the reform and comes up with several practical solutions.
\end{abstract}

\section{Main Content of Holistic Governance Theory}

\section{Concepts of Some Key Words}

The Definition of Holism. Perri Six, an English scholar who is one of the main representatives of the theory of Holistic Governance, once said, "What holistic governance aims at is a series of issues which are brought by Fragmentation Governance, and the opposite of holism is fragmentation rather than specialization." Holism is to explicit the responsibilities of every subject further under the circumstance of subjective disorder for the purpose of realizing the comprehensive coordination of multiple-subject.

In the context of the governance theory, holism is to avoid making the division of the privileges between the departments divided by domestic authorities vague, as well as to prevent the inefficiency of government administration caused by the uncertainty of right and responsibility between departments from happening.

The Definition of Governance. The "governance" was born out of words like administration, regulation and so on in the context of reform in the governmental ruling style among countries around the world. The Commission on Global Governance in United Nations made related descriptions of "governance" in the research report entitled "Our Global Partnership" in 1995, and it said ,"Governance is the sum total of various ways in which public and private organizations administrate public affairs. It is the continual process that making conflicting or different interests coordinate and take joint actions. It includes both formal systems and rules which have the right to compel obedience from people and various institutional arrangement of informal obedience which people and organizations agree on or regard as fitting their interests."

To some extent, governance optimizes administration in subjects and the relations between subjects. In the background of information era, governance can be seen as the multiple-subject process that the government balances every group interests and coordinates public affairs.

\section{The Overview of the Theory of Holistic Governance}

According to the theory of Holistic Governance proposed by Perri Six, the core of "holistic government" is to achieve the goals of public administration by the integration of every department 
and factor of administration which are independent of one another, the integration of departments with different administrative levels in the government, the integration of the government and the society, the direct and benign coordination, the interaction between the government and citizens and the integration between society and society, and integration is the most essential connotation of holistic government.

The western countries were generally faced with issues on governmental fragmentation and hollowing in the 1990s. In the book entitled "Holistic Government" which was published in 1997, Perri Six, who is a pioneer in government administration to advocate holistic governance, has proposed that the theme of government administration has experienced profound changes, namely "solving social and economic problems by making use of 'Joined-up Government' or 'Whole of Government' ". In the following research on the theory of Holistic Governance, he criticizes the viewpoint of public departments which persist in division in responsibilities and authorities, as well as sector-based in his book entitled " Towards Holistic Governance: The New Reform Agenda" , and it says that instead of overlooking alone fight between departments with different functions and professions, the government of the 21 th century should promote holistic governance, implementing the communication and coordination between all the government organs by carrying out institutionalization. In the book, "Holistic Governance" is defined as "law enforcement aiming at mutually reinforcing effect and tight cooperation between the official organizations at the basis of full communication and cooperation, effective coordination and integration, consistent policy objectives and joint executive means for the policy." The ultimate goal of Holistic Governance is to obtain the public interests and responsibilities and supply social effects with lower cost and better quality for the society, as well as more effective services.

The overall operation of the government carrying out holistic governance in policy, control, service and supervision are embodied in the following three aspects: First, integrate governance with different or the same level, such as the central and regional authorities, and different departments in the regional authorities. Second, coordinate in some functions, for example, make the army, navy and air force cooperate with each other; or coordinate between a few or many functions, such as health security and social security. Finally, coordinate in the public departments, or between government sector and non-government sector or private sector, and put all the actual situations about implementation of governance into the space-time cube model made up of three dimensions: level, function and sector.

\section{Appliance of Holistic Governance Theory: Regional Integration Reform of Customs Clearance}

\section{Regional Integration in Foreign Countries (the European Union as examples)}

European Union is the highest level of integration of political and economic organization in the world. The initiative in European integration of regional cooperation guides a wave of regional integration in the world. The success of the European regional integration is enlightenment for the development of regional integration in Yangtze River Delta. In essence, the process of European economic integration is a process of multinational institutional innovation. Europe established a series of laws to coordinate the cooperation of each member. The European Union successfully established the world's highest level of integration organization through institutional provisions of the laws and regulations of each country unified regulation.

The success of European Union is that it set up innovative systems, including European monetary system, compensation mechanism and the information sharing platform. They also established the European common market system. These innovative systems insure the internal coordination of the European Union and the stability of the long-term development of European Union.

Chinese customs is being enlightened by the progress of the European experience to further regional integration. China realized that a regional administrative system of completion, 
concreteness and unification shall be established firstly to manage the different customs districts in the region. On this basis, customs can set up an information sharing system to connect districts and remedy gaps of distance.

\section{Regional Customs Integration in China}

Beijing-Tianjin-Hebei (Jing-jin-ji) Regional Customs Integration. Early May in 2014, China General Administration of Customs issued the reform program of Beijing-Tianjin-Hebei (Jing-jin-ji) regional customs integration, clearly putting forward the important national strategy of coordinated development by customs clearance integration of the Jing-jin-ji region, symbolizing a new milestone of China customs management and operation mode.

At the same time, early July in 2014, the reform program was taken the lead in Tianjin and Beijing customs, around October gradually expanded to Shijiazhuang customs, implementing overall reform of Jing-jin-ji customs. The characteristics of the Jing-jin-ji regional customs integration is mainly manifested in regional integration as one center and four platforms, namely unified declaration, risk prevention and control, professional single trial and field operation. The one-center-four-platform helps Jing-jin-ji customs do a better job policing bonded supervision, combatting smuggling, business management and enterprises inspection.

Practical Significance of Jing-jin-ji Regional Customs Integration. Unbalanced regional economic development is one of the inevitable problems in the process of economic development, particularly prominent in developing countries as China. Actually, the regional economic gap in China is gradually widening, which is against the development of our country's economy. The regional economic difference has always been the focus of the national economic scholars' research and is also one of China's concerns.

Around the capital Beijing, Jing-jin-ji region is equipped with the foundation of regional economic development with good resources like talent, technology, money, etc. The development of Jing-jin-ji region customs clearance reform is conducive to the development of economy. Thus the problem of coordination of regional economic gap in north China can be narrowed.

The implementation of Jing-jin-ji regional customs clearance reform at the same time gets welfare for the local enterprises. Companies in three districts are regarded as from one region. It eases the limitation of customs clearance for enterprises.

\section{The present status of the regional customs clearance integration implementation in China}

The general administration of customs expands the scope of regional customs clearance integration reform, in order to build a new support of China's economy and speed up the economic integration of regional customs reforms.

Since December 1st, 2014, Nanchang, Wuhan, Changsha, Chongqing, Chengdu, Guiyang and Kunming customs officially adopted the regional integration of customs clearance. Yangtze River Delta, originally including Shanghai, Ningbo, Hangzhou and Nanjing customs, is broadened the range to the whole Yangtze River valley.

With regard to Guangdong area, after implemented from September 22nd in the sea ports and air ports, the regional customs clearance integration reform was officially adopted on December 1 st in the land ports. Thus far, the customs clearance model has universally covered all ports and all the mode of transportation in the province, applicable for all import and export goods in the areas of Guangdong port.

\section{Prospect of Appliance of Holistic Governance Theory in China Customs}

\section{Set up big data platform and perfect system of cloud computing}

At present, China customs already have the customs enforcement evaluation system and the import and export commodities monitoring and early warning system. However, because of the fast 
pace of the development of science and technology, we are not allowed to be satisfied with the current big data platforms.

China customs should promote the integrity of the customs supervision management in the area of information technology. Besides, a big data platform and cloud computing should be established immediately to make customs supervision more technological and keep up with the world trend.

We think the big data platform shall be applied in the regional integration, from the general customs administration to the customs, including directly competent customs and their subsidiaries in this area. Apart from customs, other administrative departments involved will also be shared with all kinds of information as Customs clearance documents during the process of clearance in the big data platform. A ticket of goods or a kind of specific information and statistics will quickly be found, which will help to find the suspects and implement the risk monitor as well.

Therefore, a big data platform is the foundation of regional integration. Simultaneously, the function of cloud computing is the key technology for the ensurance of smooth operation of the platform. Take the main function of customs clearance at the current regional integration as example, presently, every customs in the integrated region audits different kinds of goods. When documents declared, big data platform can analyze the information on the documents and automatic classify them and directly transmit to the customs specially auditing this kind of goods. The process will be mostly technical rather than artificial, and greatly enhancing the efficiency of customs clearance and reducing the risk of integrity

\section{Comprehensive Implementation of Customs Clearance Integration in Yangtze River Basin}

Hitherto ad, the Yangtze River Delta region has achieved the process of regional integration, opening an operation form as "one-time declaration, one-time inspection, one-time clearance" across the regional customs, which facilitates the cross-regional customs clearance in the region for enterprises.

Early in 2007, a basic system of associated meeting in the Yangtze River Delta region has been established. And as we referred above, December $1^{\text {st }}$ in this year, other seven customs applied the regional integration of customs clearance. Generally speaking, the area of the customs clearance integration has been widened to the whole Yangtze River basin.

Nevertheless, taking a broad view to requirements of the modern world, the region clearance integration of the Yangtze River basin is, to great extent, promoted by coastal-area customs, namely Shanghai, Nanjing, Ningbo, Hangzhou customs. Though one-third of the national customs volume does these four customs constitute, the regional integration didn't spur the less-developed area on.

Consequently, there is still a long way for overall construction of customs clearance integration in the Yangtze River basin to go. Regional government should improve the administrative management system and resource sharing mechanism by taking full account of the commonness and characteristics of Yangtze River basin. The system and mechanism need a larger information platform of electronic data, which can achieve rapid communication among different customs and departments.

The process also needs the experiences of regional integration in Yangtze River delta, Pearl River delta and Jing-jin-ji region. Totally speaking, the aim of regional integration is to set up an effective mechanism of regional government cooperation and to promote regional economic integration, ultimately building the unified national market.

\section{Regional Customs Clearance Center across the Country}

At present, China has set up three regional centers, viz, the Yangtze River basin, Jing-jin-ji region and Guangdong area for examination of documents. Centers are set up for the experiment of a foreseeable, low cost, efficient and convenient customs clearance environment. Customs in one region follow consolidated standards of operation specification, technological process and enforcement standard so that companies enjoy the same treatment. 
We think it would be possible in the future for setting up a larger area of regional customs clearance center across the country, realizing the whole national customs seemed like one.

\section{Acknowledgement}

This research was financially supported by Innovation Program of Shanghai Municipal Education Commission, China (NO.12YZ191).

\section{References}

[1] Perri Six, Holistic government [M], London: Demos, 1997.

[2] Perri Six, Towards Holistic Governance: The New Reform Agenda, Hound mills, Basingstoke, Hampshire: PALGRAVE, 2002:2-37.

[3] Information on http://news.163.com/14/0618/18/9V1RKOO500014JB5.html.

[4] Information on http://news.hexun.com/2014-12-01/170969985.html. 